\title{
Virtual Interviews for Sports Medicine Fellowship Positions Save Time and Money but Don't Replace In-Person Meetings
}

\author{
Sean C. Clark, M.S., Matthew J. Kraeutler, M.D., Eric C. McCarty, M.D., and \\ Mary K. Mulcahey, M.D.
}

\begin{abstract}
Purpose: To understand the perceptions of program directors (PDs) and fellowship applicants regarding the virtual interview process for orthopaedic surgery sports medicine fellowship programs. Methods: An anonymous online survey was distributed through the American Orthopaedic Society for Sports Medicine (AOSSM) to applicants and PDs of orthopaedic surgery sports medicine fellowship programs following the 2020-2021 fellowship application cycle. Results: A total of 40 responses were received from PDs for a response rate of $47 \%$ (40 of 85 ) and 72 responses were received from applicants for a response rate of $27 \%$ (72 of 271 ). All of the surveyed PDs (40/40, 100\%) agreed/strongly agreed that the applicant's interview carries significant weight in determining where an applicant is ranked on the match list. Fifty-eight percent (23 of 40) of PDs agreed/strongly agreed that virtual interviews negatively affected their personal connection with the fellowship interviewee. The presence of virtual interviews allowed $80 \%$ (57 of 71) of applicants to go on more interviews. Seventy-three percent (51 of 70) of applicants were able to save greater than $\$ 5,000$ on travel expenses and $63 \%$ (25 of 40) of fellowship programs were able to save greater than $\$ 2,500$ by conducting virtual interviews. Conclusions: Virtual interviews allowed fellowship programs and applicants to complete more interviews, but both PDs and applicants stated that interviewing in-person was important for applicants to meet faculty and tour the institution where they may be spending a year. In contrast, significant financial savings resulted due to the transition to virtual interviews. Finally, both PDs and applicants were in favor of having the option of interviewing virtually, suggesting that virtual interviews may continue to play a role in future application cycles. Clinical Relevance: This study may be valuable to fellowship programs that will continue to implement virtual interviews into future application cycles.
\end{abstract}

$\mathbf{O}$ rthopaedic surgery is becoming increasingly subspecialized, as the number of fellowship-trained orthopaedic surgeons has increased from $76 \%$ in 2003 to $90 \%$ in $2013 .{ }^{1}$ Commonly, orthopaedic surgery residents apply for fellowship during their postgraduate year 4 (PGY-4) and attend in-person interviews at their

From the Department of Orthopaedic Surgery (M.K.M.), Tulane University School of Medicine (S.C.C., M.K.M.), New Orleans, Louisiana; Department of Orthopaedic Surgery, St. Joseph's University Medical Center, Paterson, New Jersey (M.J.K.); and Department of Orthopedics, University of Colorado School of Medicine, Aurora, Colorado (E.C.M.), U.S.A.

The authors report the following potential conflicts of interest or sources of funding: E.C.M. reports personal fees from Biomet, Elsevier, and Zimmer, outside the submitted work; board or committee member, American Orthopaedic Society for Sports Medicine; research support from Arthrex, United States, Breg, and DJ Orthopaedics; board or committee member, International Society of Arthroscopy, Knee Surgery, and Orthopaedic Sports Medicine; research support from Mitek; editorial or governing board, Orthopaedics Today and American Journal of Sports Medicine; and research support from Ossur, Iceland and Smith $\theta$ Nephew, United Kingdom. M.K.M. reports board or committee member, American Academy of Orthopaedic Surgeons; editorial or governing board, American Journal of Sports Medicine fellowship programs of interest. However, the coronavirus disease 2019 (COVID-19) (severe acute respiratory syndrome coronavirus 2) pandemic has disrupted the medical, educational, and professional landscape for medical students, residents, and fellows. ${ }^{2-5}$ As a result, interviews for residency programs and clinical

Electronic Media; board or committee member, American Orthopaedic Association and American Orthopaedic Society for Sports Medicine; editorial or governing board, Arthroscopy; board or committee member, AANA; editorial or governing board, Ortho Info.; and board or committee member, Ruth Jackson Orthopaedic Society and The Forum. Full ICMJE author disclosure forms are available for this article online, as supplementary material.

Received August 4, 2021; accepted November 30, 2021.

Address correspondence to Mary K. Mulcahey, M.D., 1430 Tulane Ave., \#8632, New Orleans, LA 70112.E-mail:mary.mulcahey.md@gmail.com

(C) 2021 THE AUTHORS. Published by Elsevier Inc. on behalf of the Arthroscopy Association of North America. This is an open access article under the CC BY-NC-ND license (http://creativecommons.org/licenses/by-nc-nd/4.0/). 2666-061X/211065

https://doi.org/10.1016/j.asmr.2021.11.023 
fellowships have transitioned from a traditional inperson format to an online or virtual format. ${ }^{6-8}$ This led to programs quickly developing their own interview process, materials, and expectations while applicants involuntarily adapted to an entirely new interview format in addition to dealing with the stress of fellowship interviews. ${ }^{9}$

Previous studies have investigated the most important factors that programs search for when ranking an applicant. ${ }^{10,11}$ Specifically, Haislup et al. ${ }^{10}$ surveyed orthopaedic surgery sports medicine fellowship program directors (PDs) to better understand the factors that PDs consider when selecting prospective fellows. The authors found that the most important factor taken into account by PDs was the quality of the applicant interview. In a similar study, Baweja et al. ${ }^{11}$ also surveyed orthopaedic sports medicine fellowship PDs and found that the fellowship interview was the most important factor in ranking fellowship applicants. Thus, the change from a traditional in-person interview to a virtual interview may significantly affect the match process for both fellowship programs and applicants.

Although recent literature has evaluated the virtual fellowship interview process, ${ }^{9,12-15}$ there have been few studies that have specifically focused on the virtual interview process for orthopaedic surgery sports medicine fellowship programs. The purpose of this study was to understand the perceptions of both PDs and fellowship applicants regarding the virtual interview process for orthopaedic surgery sports medicine fellowship programs. The authors hypothesized that both PDs and fellowship applicants would prefer in-person interviews despite the considerable cost savings of virtual interviews.

\section{Methods}

An exemption was obtained from the Tulane University Biomedical Institutional Review Board (2021001). Following the 2020-2021 fellowship application cycle, online surveys using Qualtrics (Seattle, WA; Provo, UT) were distributed through the American
Orthopaedic Society for Sports Medicine to all orthopaedic surgery sports medicine fellowship applicants and PDs participating in the San Francisco Match (Appendix Tables 1 and 2, available at wwW. arthroscopyjournal.org). Follow-up e-mails were sent 2 and 4 weeks after the initial e-mail to encourage more participation.

Many items in the surveys were rated on a 5-point Likert scale. Questions in the survey distributed to the fellowship applicants included whether virtual interviews negatively affected their personal connection with the fellowship program, whether they would rather complete a preliminary virtual interview at a program followed by an in-person interview, and how much money they saved in total travel expenses as a result of the virtual format. PDs were asked if the structure of their interview day changed given the virtual format and whether programs should offer both in-person and virtual interviews once the COVID-19 pandemic ends.

\section{Results}

A total of 40 responses were received from PDs, for a response rate of $47 \%$ ( 40 of 85 ), and 72 responses were received from applicants for a response rate of $27 \%(72$ of 271). One hundred percent of PDs (40 of 40) who responded agreed/strongly agreed that the applicant's interview carries significant weight in determining where the applicant is ranked on the match list. Seventy-seven percent of PDs (30 of 39) and 65\% (47 of 72) of applicants stated that they preferred in-person interviews, whereas 15\% (6 of 39) of PDs and 29\% (21 of 72) of applicants preferred virtual interviews (Fig 1). Seventy-five percent (30 of 40) of PDs and 68\% (49 of 72 ) of applicants said it was important/very important to interview in-person. Eighty-five percent (34 of 40) of PDs and $67 \%$ (48 of 72 ) of applicants thought it was important/very important to meet their faculty members in-person. Eighty percent (32 of 40) of PDs and $67 \%$ of applicants (48 of 72 ) thought it was important/
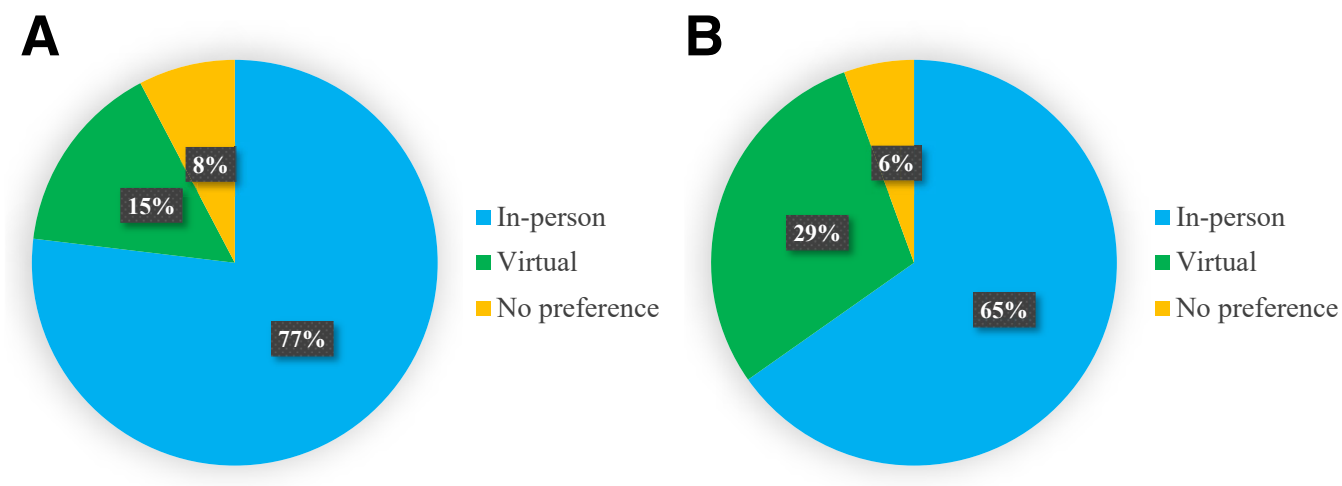

Fig 1. Preferences of sports medicine program directors (A) and applicants (B) for in-person and virtual interviews. 
Fig 2. Changes made by sports medicine fellowship programs to their interview process as a result of the coronavirus disease 2019 pandemic.

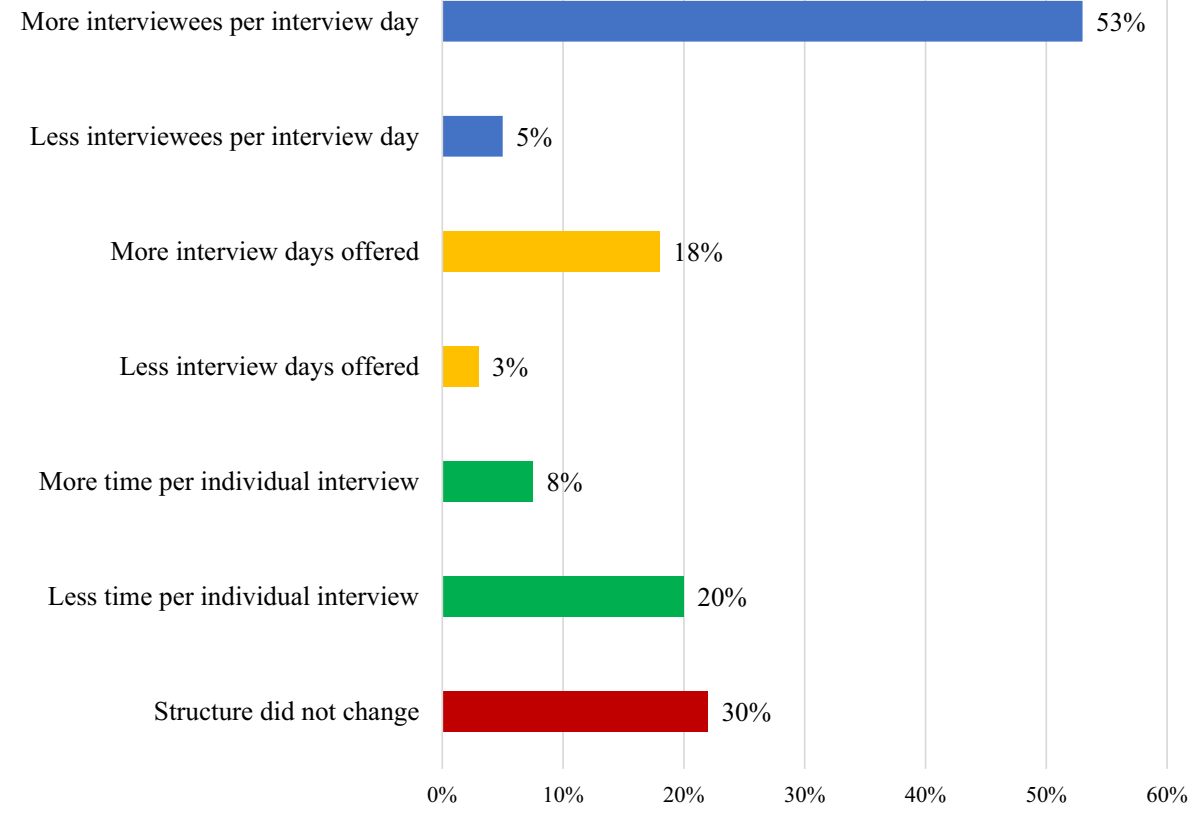

very important that applicants tour the institutions and facilities in-person.

Fifty-eight percent (23 of 40) of PDs agreed/strongly agreed that conducting virtual interviews negatively affected their personal connection with the fellowship interviewee, whereas $43 \%$ (31 of 72 ) of applicants agreed/strongly agreed that virtual interviews negatively affected their personal connection with the fellowship program. Forty percent (16 of 40) of PDs agreed/strongly agreed that they were concerned that the virtual interview process will affect the quality of applicant that matches at their program. When applicants were asked if virtual interviews will negatively affect their ability to match at their desired programs, only $29 \%$ (21 of 72 ) of applicants agreed/strongly agreed.

PDs were asked if the structure of their interview day changed, given the virtual format. Fifty-three percent (21 of 40 ) had more interviewees per interview day, $20 \%$ (8 of 40 ) had less time per individual interview, $18 \%$ (7 of 40 ) offered more interview dates, and 30\% (12 of 40) did not change their structure (Fig 2). Sixty percent of PDs (24 of 40) stated that virtual interviews resulted in their respective program interviewing more applicants than usual, whereas the presence of virtual interviews allowed $80 \%$ (57 of 71 ) of applicants to go on more interviews. Fifty-two percent (37 of 71) of applicants stated that the presence of virtual interviews did not cause them to apply to more programs, whereas $45 \%$ (32 of 71) stated that it did.

Sixty percent of PDs (24 of 40) agreed/strongly agreed that once the COVID-19 pandemic ends, programs should offer both in-person and virtual interviews. If both in-person and virtual interview opportunities are available for applicants and an applicant chooses a virtual over an in-person interview, 58\% (23 of 40) of PDs agreed/strongly agreed that this would make the fellowship interviewee appear less dedicated to the program. Sixty-five percent of applicants (47 of 72) agreed/strongly agreed that programs should give applicants the choice between in-person or virtual interviews. When asked if they would prefer to do a preliminary virtual interview followed by an in-person interview, $20 \%$ ( 8 of 40 ) of PDs and $43 \%$ (31 of 72 ) of applicants agreed/strongly agreed.

When asked how much money their fellowship program saved in the interview season by offering virtual interviews, $33 \%$ of PDs (13 of 40 ) saved between $\$ 1$ and $\$ 2,500,28 \%$ (11 of 40 ) between $\$ 2,501$ and $\$ 5,000$, and $20 \%$ (8 of 40 ) between $\$ 5,001$ and $\$ 7,500$ (Fig 3A). When asked how much money applicants saved in total travel expenses through the virtual interview process, $17 \%$ (12 of 70 ) saved between $\$ 2,501$ and $\$ 5,000,27 \%$ (19 of 70 ) saved between $\$ 5,001$ and $\$ 7,500,26 \%$ (18 of 70 ) between $\$ 7,500$ and $\$ 10,000$, and $20 \%$ (14 of 70 ) more than $\$ 10,000$ (Fig 3B).

Fifty-five percent (22 of 40) of PDs thought the transition from in-person to virtual interviews was easy/very easy and $84 \%$ (27 of 32) used Zoom as their interview software/platform. Thirty-three percent (14 of 40) of PDs and $58 \%$ of applicants (41 of 71 ) agreed/strongly agreed that they were concerned about computer technical difficulties while conducting a virtual interview. 

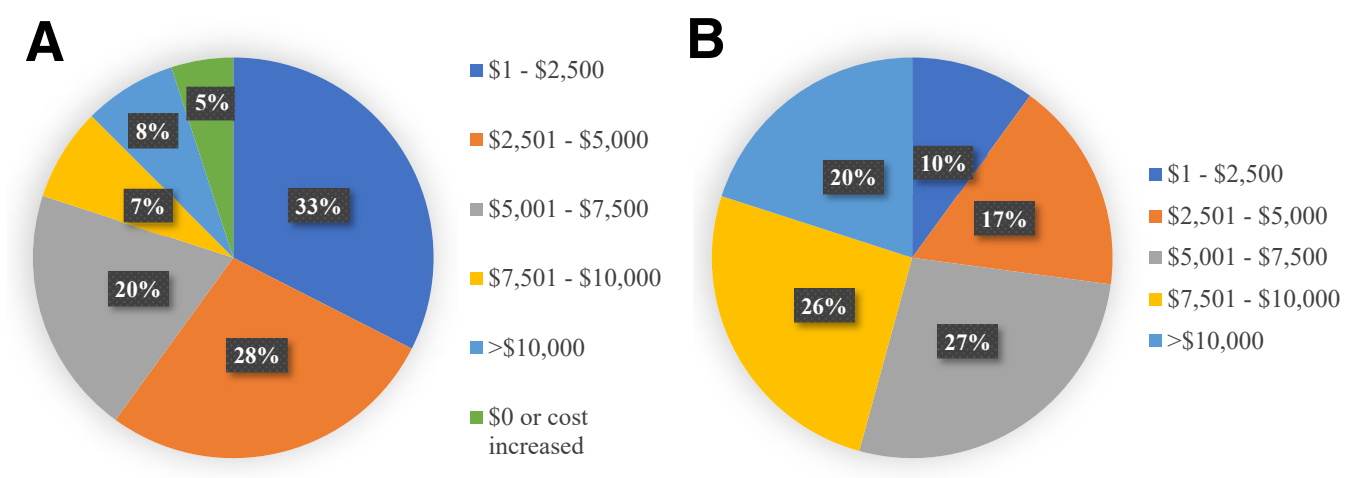

Fig 3. Costs saved by orthopaedic sports medicine fellowship programs (A) and applicants (B) as a result of transitioning to virtual interviews.

\section{Discussion}

Based on the results of this study, the interview process for applicants of orthopaedic sports medicine fellowship programs is critical, as $100 \%$ of the surveyed PDs agreed/strongly agreed that the applicant's interview carries significant weight in determining where the applicant is ranked on the match list. This study was performed to reflect on the recent transition of fellowship interviews from in-person to virtual due to the COVID-19 pandemic. Interviewing virtually may have significantly impacted the match process as $58 \%$ of PDs agreed/strongly agreed that virtual interviews negatively affected their personal connection with the fellowship interviewee and $40 \%$ agreed/strongly agreed that they were concerned that the virtual interview process will affect the quality of applicant that matches to their program. This may have led fellowship programs to rely more heavily on letters of recommendation or personal phone calls as previous studies have shown the importance of personal connections in the match process. ${ }^{10,16}$ Yong et al. ${ }^{17}$ assessed the perspectives of fellowship directors and applicants regarding the virtual interview process for orthopaedic surgery trauma fellowships. The authors found that $75 \%$ of fellowship directors stated that virtual interviews limited their ability to familiarize themselves with an applicant and only $50 \%$ reported that they were comfortable ranking an applicant after a virtual interview. In contrast, Vadi et al. ${ }^{18}$ compared match rates at an anesthesiology residency program between applicants who completed inperson interviews versus those who completed virtual interviews. The authors found no significant difference in match rate between the groups.

In this study, a large proportion of PDs and applicants stated that it was important/very important to interview in-person, to meet the faculty members in-person, and to tour the institution in-person. Without being able to visit the program in-person, the applicant may not have a sense of the program culture, resources available, and whether or not they will enjoy living in the area for a year. ${ }^{19,20}$ Similarly, Chandler et al. ${ }^{21}$ surveyed residents applying to a pediatric surgery fellowship at a single institution and found that only $35 \%$ believed that virtual interviews allowed them to decide if the program was the right fit for them. Bamba et al. ${ }^{22}$ surveyed applicants who interviewed at a plastic surgery residency program and found that those who interviewed in-person felt more acquainted with the program, faculty, and residents more than those who interviewed virtually.

Regarding future fellowship application cycles, $60 \%$ of PDs agreed/strongly agreed that programs should offer both in-person and virtual interviews and $65 \%$ of applicants agreed/strongly agreed that applicants should be given the choice between in-person and virtual interviews. Robinson et al..$^{23}$ found that $79 \%$ of cardiothoracic surgery fellowship PDs and 55\% of applicants agreed/strongly agreed that virtual interviews should be offered in the future, yet $85 \%$ of PDs and $80 \%$ of applicants agreed/strongly agreed that virtual interviews should be offered with the option of an inperson interview. Interestingly, if both in-person and virtual interviews were offered and an applicant chose a virtual over an in-person interview, $58 \%$ of PDs agreed/strongly agreed that this would make the interviewee appear less dedicated to the program. This may create a bias in favor of applicants who can afford to travel to in-person interviews. ${ }^{8}$ Although PDs and applicants believe that both in-person and virtual interviews should be offered in the future, only $20 \%$ of PDs and $44 \%$ of applicants agreed/strongly agreed that they would prefer to complete a preliminary virtual interview followed by an in-person interview.

One benefit of the virtual interview process is cost savings. ${ }^{24}$ More than $80 \%$ of applicants were able to save greater than $\$ 5,000$, whereas $60 \%$ of fellowship programs were able to save greater than $\$ 2,500$ (Fig 3). Before the global pandemic, a study by Oladeji et al. ${ }^{25}$ surveyed orthopaedic surgery residency PDs and residents regarding the in-person fellowship interview process. The authors found that residents spent an 
average of 11 days away from their residency programs and $\$ 5,875$ on total travel costs. A separate study performed a literature review of the costs of attending surgical fellowship interviews and found that applicants saved close to $\$ 6,000$ in travel expenses with virtual interviews. ${ }^{26}$ Finally, Vining et al. ${ }^{27}$ surveyed residents applying to surgical oncology fellowships and found that respondents favored the cost and time savings, increased efficiency, and decreased stress related to travel as benefits of virtual interviews.

Efficiency is another benefit of the virtual interview process, as $53 \%$ ( 21 of 40 ) of fellowship programs had more interviewees per interview day and $60 \%$ (24 of 40 ) interviewed more applicants than usual. In addition, interviewing virtually allowed $80 \%$ (57 of 71) of applicants to go on more interviews. Even though virtual interviews may affect the personal connection between the interviewee and interviewer, and the ability of the applicant to get a feel for the program, it allows applicants to interview at more programs and programs to interview more applicants. This may benefit the more qualified applicants, as they may be able to attend more interviews and potentially take away interview opportunities from applicants who are less qualified. Regardless, 207 of 222 (93\%) positions were filled across the participating sports medicine fellowship programs, which was similar to previous years. ${ }^{28}$ Bates et al. $^{29}$ provided perspectives on the virtual interview process for radiation oncology residency programs and stated that virtual interviews led to increased efficiency by allowing residency programs to interview more applicants per day while allowing faculty to maintain their clinical duties. In addition, the reduced costs of the virtual interviews allowed applicants to attend more interviews and fellowship programs to interview more total applicants.

\section{Limitations}

There are limitations to this study, including the relatively low response rate from both PDs and applicants. Thus, this study may not reflect the perceptions of all orthopaedic sports medicine fellowship PDs and applicants. In addition, the sample size was small, as this was a cross-sectional study and PDs and applicants were surveyed following only one application cycle. Recall bias may have played a role in survey responses, as surveys were completed after the fellowship match rather than in the middle of the interview season. Finally, the results are subject to responder bias, as fellowship programs' and applicants' perceptions may have been based on their match results.

\section{Conclusions}

Virtual interviews allowed fellowship programs and applicants to complete more interviews, but both PDs and applicants stated that interviewing in-person was important for applicants to meet faculty and tour the institution where they may be spending a year. In contrast, significant financial savings resulted due to the transition to virtual interviews. Finally, both PDs and applicants were in favor of having the option of interviewing virtually, suggesting that virtual interviews may continue to play a role in future application cycles.

\section{References}

1. Horst PK, Choo K, Bharucha N, Vail TP. Graduates of orthopaedic residency training are increasingly subspecialized: A review of the American Board of Orthopaedic Surgery Part II database. J Bone Joint Surg Am 2015;97:869-875. doi:10.2106/jbjs.N.00995.

2. Kogan M, Klein SE, Hannon CP, Nolte MT. Orthopaedic education during the COVID-19 pandemic. J Am Acad Orthop Surg 2020;28:e456-e464. doi:10.5435/jaaos-d-2000292.

3. Binks AP, LeClair RJ, Willey JM, et al. Changing medical education, overnight: the curricular response to COVID19 of nine medical schools. Teach Learn Med 2021;33: 334-342. doi:10.1080/10401334.2021.1891543.

4. Franklin G, Martin C, Ruszaj M, et al. How the COVID-19 pandemic impacted medical education during the last year of medical school: A class survey. Life (Basel) 2021;11. doi:10.3390/life 11040294.

5. Peebles LA, Kraeutler MJ, Waterman BR, Sherman SL, Mulcahey MK. The impact of COVID-19 on the orthopaedic sports medicine fellowship application process. Arthrosc Sports Med Rehabil 2021;3:e1237-e1241. doi:10. 1016/j.asmr.2021.04.002.

6. Aiyer AA, Granger CJ, McCormick KL, et al. The impact of COVID-19 on the orthopaedic surgery residency application process. J Am Acad Orthop Surg 2020;28:e633-e641. doi:10.5435/jaaos-d-20-00557.

7. Deitte LA, Mian AZ, Esfahani SA, Hu J-Y. Going virtual: Redesigning the interview experience. J American Coll Radiol 2021;18:337-339. doi:10.1016/j.jacr.2020.06.021.

8. Wright AS. Virtual interviews for fellowship and residency applications are effective replacements for inperson interviews and should continue post-COVID. J Am Coll Surg 2020;231:678-680. doi:10.1016/j.jamcollsurg.2020.09.005.

9. DiGiusto M, Lupa MC, Corridore M, Sivak EL, Lockman JL. The impact of the COVID-19 pandemic on the 2020 pediatric anesthesiology fellowship application cycle: A survey of applicants. Paediatr Anaesth 2021;31: 968-976. doi:10.1111/pan.14226.

10. Haislup BD, Kraeutler MJ, Baweja R, McCarty EC, Mulcahey MK. Orthopaedic sports medicine fellowship interviews: Structure and organization of the interview day. Orthop J Sports Med 2017;5:2325967117741276, https://doi.org/10.1177/2325967117741276.

11. Baweja R, Kraeutler MJ, Mulcahey MK, McCarty EC. Determining the most important factors involved in ranking orthopaedic sports medicine fellowship applicants. Orthop J Sports Med 2017;5:2325967117736726, https://doi.org/10.1177/2325967117736726.

12. Chang TC, Hodapp EA, Parrish RK, et al. Virtual versus inperson surgical fellowship interviews and ranking 
variability: The COVID-19 experience. Res Sq 2021. rs.3. rs-415697, https://doi.org/10.21203/rs.3.rs-415697/v1.

13. Hamade N, Bhavsar-Burke I, Jansson-Knodell C, et al. Virtual gastroenterology fellowship recruitment during COVID-19 and its implications for the future. Dig Dis Sci 2021;May:1-10. doi:10.1007/s10620-021-07014-1.

14. Rojas KE, Teshome M, Tevis SE. Unforeseen collateral damage of COVID-19 with the virtualization of fellowship interviews. Ann Surg 2021;273:e271-e272. doi:10.1097/ sla.0000000000004850.

15. Kraeutler MJ. An applicant's review of virtual fellowship interviews: The new norm? Arthroscopy 2021;37: 1704-1705. doi:10.1016/j.arthro.2021.04.020.

16. Bernatz JT, Johnson KP, Stokman JJ, Cannada LK, Williams SK, Whiting PS. Factors considered in ranking spine surgery fellowship applicants: A survey of program directors. Spine (Phila Pa 1976) 2021;46:882-885. doi:10. 1097/brs.0000000000003938.

17. Yong TM, Davis ME, Coe MP, Perdue AM, Obremskey WT, Gitajn IL. Recommendations on the use of virtual interviews in the orthopaedic trauma fellowship match: A survey of applicant and fellowship director perspectives. OTA Int 2021;4:e130. doi:10.1097/OI9. 0000000000000130.

18. Vadi MG, Malkin MR, Lenart J, Stier GR, Gatling JW, Applegate RL 2nd. Comparison of web-based and face-toface interviews for application to an anesthesiology training program: A pilot study. Int J Med Educ 2016;7: 102-108. doi:10.5116/ijme.56e5.491a.

19. Mallepally N, Bilal M, Hernandez-Barco YG, Simons M, Berzin TM, Oxentenko AS. The new virtual reality: How COVID-19 will affect the gastroenterology and hepatology fellowship match. Dig Dis Sci 2020;65:2164-2168. doi:10. 1007/s10620-020-06432-x.

20. Tawfik AM, Imbergamo C, Chen V, et al. Perspectives on the orthopaedic surgery residency application process during the COVID-19 pandemic. J Am Acad Orthop Surg Glob Res Rev 2021;5:e21.00091. doi:10.5435/JAAOSGlobal-D-21-00091.
21. Chandler NM, Litz CN, Chang HL, Danielson PD. Efficacy of videoconference interviews in the pediatric surgery match. J Surg Educ 2019;76:420-426. doi:10.1016/j.jsurg. 2018.08.010.

22. Bamba R, Bhagat N, Tran PC, Westrick E, Hassanein AH, Wooden WA. Virtual interviews for the independent plastic surgery match: A modern convenience or a modern misrepresentation? J Surg Educ 2020;78:612-621. doi: 10.1016/j.jsurg.2020.07.038.

23. Robinson KA, Shin B, Gangadharan SP. A comparison between in-person and virtual fellowship interviews during the COVID-19 pandemic. J Surg Educ 2020;78: 1175-1181. doi:10.1016/j.jsurg.2020.11.006.

24. Hagedorn JCI, Chen J, Weiss WM, Fredrickson SW, Faillace JJ. Interviewing in the wake of COVID-19: How orthopaedic residencies, fellowships, and applicants should prepare for virtual interviews. J Am Acad Orthop Surg 2021;29:271-277. doi:10.5435/jaaos-d-20-01148.

25. Oladeji LO, Pehler SF, Raley JA, Khoury JG, Ponce BA. Is the orthopedic fellowship interview process broken? A survey of program directors and residents. Am J Orthop (Belle Mead NJ) 2015;44:E444-E453.

26. Tseng J. How has COVID-19 affected the costs of the surgical fellowship interview process? J Surg Educ 2020;77:999-1004. doi:10.1016/j.jsurg.2020.05.018.

27. Vining CC, Eng OS, Hogg ME, et al. Virtual surgical fellowship recruitment during COVID-19 and its implications for resident/fellow recruitment in the future. Ann Surg Oncol 2020;27:911-915. doi:10.1245/s10434-02008623-2 (suppl 3).

28. Mulcahey MK, Hayes MK, Smith CM, Kraeutler MJ, Trojan JD, McCarty EC. Outcomes in the orthopaedic sports medicine fellowship match, 2010-2017. Orthop J Sports Med 2018;6:2325967118771845-2325967118771845, https:// doi.org/10.1177/2325967118771845.

29. Bates JE, De Leo AN, Malouff TD, et al. Resident considerations for virtual interviews in radiation oncology: Perspectives from the Sunshine State. Adv Radiat Oncol 2020;6:100591. doi:10.1016/j.adro.2020.09.024. 
Appendix Table 1. Orthopaedic Sports Medicine Fellowship Applicants' Survey

1. Do you prefer in-person or virtual interviews?

- In-person

- Virtual

- No preference

2. How important is it for you to interview in-person?

- Very Important

- Important

- Neutral

- Unimportant

- Very Unimportant

3. How important is it that you meet the program's faculty members in-person?

- Very Important

- Important

- Neutral

- Unimportant

- Very Unimportant

4. How important is it that you tour the program's institution and facilities in-person?

- Very Important

- Important

- Neutral

- Unimportant

- Very Unimportant

5. Virtual interviews negatively affected my personal connection with the fellowship program.

- Strongly Agree

- Agree

- Neutral

- Disagree

- Strongly Disagree

6. Virtual interviews resulted in meeting fewer faculty members.

- Strongly Agree

- Agree

- Neutral

- Disagree

- Strongly Disagree

7. Once the COVID-19 pandemic is over, programs should give applicants the choice between either in-person or virtual interviews.
- Strongly Agree
- Agree
- Neutral
- Disagree
- Strongly Disagree

8. I would prefer to do a preliminary virtual interview at a program followed by an in-person interview.

- Strongly Agree

- Agree

- Neutral

- Disagree

- Strongly Disagree

9. Virtual interviews will negatively affect my ability to match at desired programs.

- Strongly Agree

- Agree

- Neutral

- Disagree

- Strongly Disagree

10. I was worried about computer technical difficulties during a virtual interview.

- Strongly Agree

- Agree

- Neutral
- Disagree

- Strongly Disagree

11. How much money did you save in total travel expenses by not having to go to in-person interviews?
- $\$ 1-\$ 2,500$
- $\$ 2,501-\$ 5,000$
- $\$ 5,001-\$ 7,500$
- $\$ 7,501-\$ 10,000$
- $>\$ 10,000$

12. How many fellowship programs did you apply to this year?
- $1-20$
- $21-40$
- 41-60
- 61-80
- 81-100

13. How many interview offers did you receive?
$\circ 0$
$\circ 1-5$
- 6-10
- $11-15$
- 16-20
- 21-25
$\circ \geq 26$

14. How many virtual interviews did you attend?
○ $0-5$
6-10
- 11-15
- 16-20
- 21-25
$0 \geq 26$

15. Did the presence of virtual interviews cause you to apply to more programs?

$\circ$ Yes

- No

- Maybe

16. Did the presence of virtual interviews allow you to go on more interviews?

- Yes
- No
- Maybe

17. Were you required by your residency program to take vacation days to attend virtual interviews?

$\circ$ Yes

- No

- Not Sure

18. In which region of the country is your residency program located?

- Northeast - CT, MA, NH, NJ, NY, PA, RI, VT

- Midwest - IN, IL, IA, KS, MI, MN, MO, NE, ND, OH, WI

- South - AL, AR, DC, KY, LA, MD, MS, NC, OK, SC, TN, TX, VA, WV

- West - AZ, CA, CO, HI, NV, NM, OR, UT, WA

19. What is your age?
$\circ<25$
- 26-30
- 31-35
- 36-40
- 41-45
- 46-50
$\circ>50$

20. Optional: With which gender do you most identify?
- Male
- Female
- Transgender Male
Transgender Female
- Gender Binary Non-Conforming 

- Other
- Prefer Not to Say

21. Optional: Are you of Hispanic, Latino, or Spanish origin?
- Yes
- No
- Prefer Not to Say

22. Optional: How would you describe yourself? (Check all that apply)

$\circ$ White

- Black or African American

- American Indian or Alaska Native

- Asian

- Native Hawaiian or Pacific Islander

- Other

\section{Appendix Table 2. Orthopaedic Sports Medicine Program}

\section{Directors' Survey}

1. Do you prefer in-person or virtual interviews?

- In-person

- Virtual

- No preference

2. How difficult was your program's transition from in-person interviews to virtual interviews?

- Very Difficult

- Difficult

- Neutral

- Easy

- Very Easy

3. How important is it for you to interview applicants in-person?

- Very Important

- Important

- Neutral

- Unimportant

- Very Unimportant

4. How important is it that your applicants meet your faculty members in-person?

- Very Important

- Important

- Neutral

- Unimportant

- Very Unimportant

5. Did your program change the structure of the interview day given the virtual format? Select all that apply.

- More interviewees per interview date

- Less interviewees per interview date

- More time per individual interview

- Less time per individual interview

- More interview dates offered

- Less interview dates offered

- Structure did not change

6. How important is it that your applicants tour your institution and facility?

- Very Important

- Important

- Neutral

- Unimportant

- Very Unimportant

7. Conducting virtual interviews negatively affected my personal connection with the fellowship interviewee.
- Strongly Agree
- Agree
Neutral
- Disagree
- Strongly Disagree

8. Once the COVID-19 pandemic is over, programs should offer both in-person and virtual interviews.

- Strongly Agree

- Agree

- Neutral

- Disagree

- Strongly Disagree

9. I would prefer to do a preliminary virtual interview with an applicant followed by an in-person interview.

- Strongly Agree

- Agree

- Neutral

- Disagree

- Strongly Disagree

10. If both in-person and virtual interview opportunities are available for applicants and an applicant chooses a virtual interview over an in-person interview, this would make the fellowship interviewee look less dedicated to the program.
- Strongly Agree
- Agree
- Neutral
- Disagree
- Strongly Disagree

11. The applicant's interview carries significant weight for where they are ranked on the match list.

- Strongly Agree

- Agree

- Neutral

- Disagree

- Strongly Disagree

12. I am concerned that the virtual interview process will affect the quality of applicant that matches at my program.

- Strongly Agree

- Agree

- Neutral

- Disagree

- Strongly Disagree

13. I was worried about computer technical difficulties while conducting a virtual interview.

- Strongly Agree

- Agree

- Neutral

- Disagree

- Strongly Disagree

14. How much money did your program save in the interview season by offering virtual interviews?

- $\$ 1-\$ 2,500$

- $\$ 2,501-\$ 5,000$

- $\$ 5,001-\$ 7,500$

- $\$ 7,501-\$ 10,000$

$>\$ 10,000$

- $\$ 0$, or virtual interviews increased cost

15. How many applicants does your program typically interview in a given year?

- $1-20$

- $21-40$

- 41-60

- 61-80

- $81-100$

$\circ>100$ 
16. Virtual interviews have allowed you to interview more applicants.

$\circ$ Yes

- No

- Maybe

17 What interview software/platform did your program use?

(Free Response)

18. How long have you been the program director of your orthopaedic surgery sports medicine fellowship program?

- 0 -4 years

- 5-9 years

- 10-14 years

- 15-19 years

$\circ \geq 20$ years

19. How many orthopaedic sports medicine faculty members (including yourself) are in your orthopaedic surgery

department?

○ $1-5$

○ 6-10

- $11-15$

- $16-20$

- 21-25

- 26-30

$\circ>30$

20. In which region of the country is your program located?

- Northeast - CT, MA, NY, PA, RI

- Midwest - IL, IA, KS, MI, MN, MO, OH, WI

- South - AL, FL, GA, KY, LA, MD, MS, NC, SC, TN, TX, VA

- West - AZ, CA, CO, NV, NM, UT

21. What is your age?
$\circ \leq 40$
- 41-45
- $46-50$
- 51-55
- 56-60
- 61-65
- 66-70
$\circ>70$

22. Optional: With which gender do you most identify?

- Male

- Female

- Transgender Male

- Transgender Female

- Gender Binary Non-Conforming

- Other

- Prefer Not to Say

23. Optional: Are you of Hispanic, Latino, or Spanish origin?

- Yes

- No

- Prefer Not to Say

24. Optional: How would you describe yourself? (Check all that apply)

$\circ$ White

- Black or African American

- American Indian or Alaska Native

- Asian

- Native Hawaiian or Pacific Islander

- Other

- Prefer Not to Say 